\title{
ІНФОРМАЦІЙНІ МОДЕЛІ ЗАГАЛЬНОГО ДОГЛЯДУ ЗА ХВОРИМИ 3 ПІДТРИМКОЮ АЛГОРИТМІВ ПРИЙНЯТТЯ РІШЕНЬ НА ОСНОВІ КЛАСИФІКАТОРА ICNP
}

\author{
В. П. Марценюк, І. Є. Андрущакㄹ, І. В. Цікорська 2 \\ Університет Бєльсько-Бяли, Республіка Польща

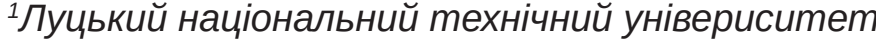 \\ ${ }^{2} Д В Н 3$ «Тернопільський державний медичний університет \\ імені І. Я. Горбачевського МОЗ України»
}

\begin{abstract}
У роботі представлено інфрормаційні моделі процесу догляду за пацієнтами шляхом концептуального представлення, що включають оцінювання стану пацієнта в цілісному вимірі (медсестринське інтерв'ю, фрізикальне дослідження, обстеження, вимірювання, аналіз документації), медсестринський діагноз, планування медсестринського догляду, визначення очікуваних результатів, медсестринських маніпуляцій, імплементацію плану догляду та евалуацію результатів догляду. Особлива увага звертається на можливості використання міжнародної термінології в описі медсестринської практики. Аналіз рішень проводиться з використанням термінології дерев рішень.
\end{abstract}

Ключові слова: процес догляду, медсестринський діагноз, медсестринські маніпуляції, класифрікація ICNP, аналіз рішень, дерево рішень.

\section{INFORMATION MODELS OF GENERAL NURSING CARE FOR PATIENTS WITH SUPPORT FOR DECISION ALGORITHMS BASED ON THE ICNP CLASSIFIER}

V. P. Martsenyuk, I. Ye. Andrushchak ${ }^{1}$, I. V. Tsikorska ${ }^{2}$

University of Bielsko-Biala, the Republic of Poland

${ }^{1}$ Lutsk National Technical University

${ }^{2}$ SHEE I. Horbachevsky Ternopil State Medical University of the Ministry of Health of Ukraine

The paper presents information models of the nursing process through a conceptual presentation, including assessments of the patient's overall condition (nursing interviews, physical assessment, measurement, documentation analysis), nursing diagnosis, nursing care planning, determination of expected results, nursing manipulation, care plan implementation and care results evaluation. Particular attention is drawn to the possibility of using international terminology in describing nursing practices. Analysis of solutions is carried out using the terminology of decision trees.

Key words: nursing process, nursing diagnosis, nursing manipulations, ICNP classification, decision analysis, decision tree.

\section{ИНФОРМАЦИОННЫЕ МОДЕЛИ ОБЩЕГО УХОДА ЗА БОЛЬНЫМИ С ПОДДЕРЖКОЙ АЛГОРИТМОВ ПРИНЯТИЯ РЕШЕНИЙ НА ОСНОВЕ КЛАССИФИКАТОРА ІСNР}

\author{
В. П. Марценюк, И. Е. Андрущакํ, И. В. Цикорская² \\ Университет Бельско-Бялы, Республика Польша \\ ${ }^{1}$ Луцкий национальный технический универиситет

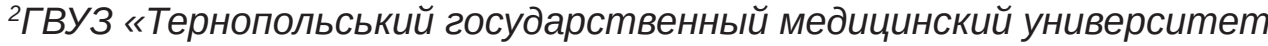 \\ имени И. Я. Горбачевского МЗ Украины»
}

\begin{abstract}
В работе представлены информационные модели процесса ухода за больными путем концептуального представления, включающие оценки состояния пациента в целостном измерении (медсестринское интервью, фризикальное обследование, измерение, анализ документации), медсестринский диагноз, планирование медсестринского ухода, определение ожидаемых результатов, медсетринских манипуляций, имплементацию плана ухода и эвалуацию результатов ухода. Особое внимание обращается на возможность использования международной терминологии в описании медсестринской практики. Анализ решений проводится с использованием терминологии деревьев решений.
\end{abstract}

Ключевые слова: процесс ухода, медсестринский диагноз, медсестринские манипуляции, классификация ICNP, анализ решений, дерево решений.

(c) В. П. Марценюк, I. Є. Андрущак, І. В. Цікорська 
Введение. Процесс ухода за больными трактуется как основной термин медсестринского ухода [7]. Он понимается как концепция рационального ухода и присутствует с давних пор в творческой медсестринской мысли и профессиональной практике. Сегодня он понимается как современный, целостный и индивидуальный уход $[5,8]$. Медсестры прилагали и прилагают усилия, чтобы проводимый ими уход отвечал запросам и критериям качества.

Цель работы: моделирование проблем, связанных с принятием решений в общем уходе за больными, с использованием структурированного подхода анализа решений и международного классификатора медсестринской практики ICNP.

Результаты и их обсуждение. В прошлом обычно применяли только некоторые элементы процесса ухода [5]. В наше время возникает необходимость предоставления индивидуального и целостного ухода на высоком уровне, тем более что Всемирная организация здравоохранения и многочисленные международные медсестринские организации рекомендуют методы работы, основанные на процессе ухода.

Современная медсестринская практика должна характеризоваться следующими свойствами [3].

1. Индивидуализация в подходе к пациенту медсестра обязана учитывать и уважать особенности, индивидуальность и уникальность каждого получателя медсестринских услуг на каждом этапе ухода.

2. Координация / коллективность ухода. Процесс ухода должен быть тесно интегрирован с процессом диагностики, терапии и выздоровления определенного пациента, которому оказывает уход команда медсестер. Они должны сотрудничать не только с самим пациентом, но также с его семьей / близкими, другими специалистами в системе здравоохранения, например с медсестрой долгосрочного ухода, врачом, диетологом, физиотерапевтом, акушеркой, психологом или социальным работником.

3. Целостный подход, характеризующийся заботой и заинтересованностью медсестры не только биологическими / физиологическими параметрами жизни подопечного, но и его психосоциальными аспектами. Необходим при этом учёт функционирования пациента в определенной социальной группе / семье, а также среде обитания / обучения / работы в сочетании с выбранным им стилем жизни.
4. Опора профессиональной практики на результаты научных исследований $[1,2]$ на всех этапах процесса ухода и критическое мышление при принятии решения. Процесс ухода использует элементы клинической мысли, что требует от медсестры умения интерпретации и применения результатов научных исследований на практике, например во время категоризации у субъекта ухода и решений, касающихся выбора определенного способа медсестринских манипуляций, направленных на улучшение функционирования пациента, включая качество его жизни, а также постоянное улучшение качества ухода.

5. Связь между безопасной профессиональной средой и уровнем медсестринского ухода и его результатами. Безопасная и здоровая профессиональная среда уменьшает риск возникновения медицинских ошибок, увеличивает эффективность ухода, а также минимизирует риск возникновения межличностных конфликтов и стрессовых ситуаций в коллективе.

Использование классификатора ICNP. Международный классификатор медицинской практики (International Classification for Nursing Practice, ICNP®) является неотъемлемой частью глобальной информационной инфраструктуры, практики и политики в области здравоохранения, направленной на улучшение здравоохранения во всем мире [4]. ICNP® - это унифицированная система медсестринского языка, терминология, используемая в практике медсестер, которая способствует согласованию терминов, используемых в конкретных лечебных учреждениях на основе существующих терминологических систем.

Целью данной работы является показать возможность использования ICNP® в процессе принятия медсестринских решений.

Современная версия ICNP® дает возможность обозначить готовые диагнозы и медсестринские манипуляции. ICNP® является международным стандартом для терминологии ухода. Классификатор установлен и разработан как специальный проект Международного совета медсестер (International Council of Nurses, ICN). Он защищен авторским правом, принадлежащим ICNP [7]. Среди причин введения классификатора в медсестринской практике чаще всего упоминаются стандартизация медсестринского словаря, возможность реализации в очень разных условиях и культурах, необходимость для медсестер описания зависимости между 
диагнозом, вмешательством и его результатом, развитие информационных систем поддержки управления здравохранением, включая медсестринский уход, поддержка додипломной и последипломной системы образования медсестер [1, 3], установление необходимых затрат на медсестринский уход, планирование ресурсов в повседневной работе, ссылки на другие медицинские системы классификации [5].

Текущая версия ICNP® от 2015 года позволяет использовать список готовых медсестринских диагнозов, вмешательств (т. е. действий / манипуляций медсестер относительно диагностических проблем) и полученных в ходе их применения результатов ухода [8].

Концепция процесса ухода. Концепция процесса ухода родилась в США в конце 1950-х годов. Авторами концепции были именно медсестры: Hildegarde Peplau (Interpersonal relations in nursing, 1952), Lydia Hall (Quality of nursing care, 1955), Dorothy Johnson (A philosophy of nursing, 1959). C 1960-х годов процесс ухода получил свою теоретическую и практическую основы.

Существует ряд подходов к определению процесса ухода. Итак, процесс ухода это:

- термин, относящийся к системе определенных процедур и манипуляций по уходу за больными, которые являются нужными для здоровья человека, семьи и/или других сообществ, а также нахождение способов для как можно лучшего удовлетворения этих потребностей (WHO, 1985);

- концепция и научный метод ухода, целью которого является повышение его уровня и эффективности, приспособления к современным потребностям человека (семьи, среды) в сфере поддержания и укрепления здоровья, а также его восстановления;

- предоставление медсестринского ухода с использованием сознательного распознавания биологического, психического, общественного, духовного, культурного состояния личности и среды;

- метод работы медсестры с пациентом и его средой, основанный на целостной концепции ухода; определяет систематизированный цикл действий;

- научный метод, применяемый медсестрами с целью обеспечения качества ухода за пациентом;

- метод, применяемый медсестрами в различных областях медсестринской практики, основанный на целостном индивидуализированном и сконцентрированном подходе к объекту ухода.

Анализ решений в общем уходе. Анализ принятия решений особенно подходит для ситуаций, в которых есть выбор четких решений, и где лица, в отношении которых принимаются решения (например, пациент), должны быть проинформированы о возможности различных результатов [6].

Анализ принятия решений базируется на теории принятия решений, известной как теория субъективной ожидаемой полезности. Эта теория предлагает модель принятия решений, то есть описывает действия, которые приведут к принятию решения, если имеющаяся информация будет использована логично и рационально. Иными словами, теория указывает на то, что лицо, принимающее решение, должно выбрать вариант с наибольшей вероятностью, что приведет к достижению результата, который будет отвечать его убеждению, учитывая ценность решения. Такое сопоставление результатов с входными данными известно как максимизация ожидаемой полезности (Bell et al., 1988).

Если речь идет об анализе решений в клинической практике, то имеем пример решения, принятого в условиях неопределенности. Фактически почти все решения в сфере здравоохранения принимаются в условиях неопределенности (Eddy, 1990). Например, непонятно, излечится ли рецидив язвенной болезни, и будет ли пациент соблюдать лечение, если ему его назначили. Возможное решение также может зависеть от того, как пациент будет чувствовать себя после лечения, а не от возможности развития еще одной язвы.

Структурирование решения возможно в формате дерева решений. В дерево встроены различные ситуации, которые могут возникнуть случайно (или неопределенно). Они включают в себя, например, ситуации: пациент будет придерживаться определенного лечения, язва будет повторяться или не будет.

Определенный набор ветвей рассматривают как узлы решения. Узлы решения представляют ситуации, заключающиеся в выборе что-либо делать (или не делать). Определенные листья дерева известны как случайные узлы, и они указывают на вероятность результата. Другие листья представляют такие ситуации в принятии решения, где результат не может быть предусмотрен с уверенностью (решение в условиях неопределенности). 
При анализе решений на основе проблемы решений обычно строится дерево решений. При структурировании проблемы таким образом и добавлении числовых значений для разных узлов, проблема может быть проанализирована, и определен выбор оптимального решения. В листьях дерева мы можем представлять как вероятность конкретного получаемого результата, так и значения (полезность), что является важным для лица, принимающего решение. Одним из преимуществ использования метода анализа решений является возможность явным образом связать результаты экспериментальных исследований с выбранными вариантами решений [6].

Этапы процесса ухода и модели принятия решений.

Этап 1: оценка. На первом этапе процесса ухода медсестра собирает информацию, касающуюся физиологического, психологического, социологического и духовно-культурного статуса пациента, а также функционального состояния и образа жизни, способности к самоуходу и проведению самоконтроля (рис. 1-3).

Оценка функционирования больного служит для идентификации актуальных и потенциальных медсестринских задач и потребностей пациента, что, в свою очередь, обусловливает сферу и характер медсестринского ухода. Медсестра обдумывает явления, оценивает размер задач, проблем с целью установления диагноза.

Это очень динамичный этап, требующий от медсестры умения установления межличностных отношений как с самим пациентом, так и с лицами из его окружения, а также членами многопрофильного коллектива. Целью такого поведения является, в том числе, получение доверия больного, побуждение его к сотрудничеству, формирование атмосферы доброжелательности опеки.

Оценивание - это не только способность к наблюдению и накоплению информации. Это прежде всего умение проведения ее анализа и интерпретации в результате критического мышления.

Для этапа оценки классификатор ICNP предусматривает ряд терминов. Ниже представлено описание понятий, используемых на этом этапе. В частности, термины «состояние» и «статус». Здесь состояние - это «мнение медсестры», тогда как «статус» является объектом исследуемого явления, результатом чего является установление медсестринского диагноза.
1. Состояние 10018786 (J) мнение медсестры.

2. Статус 10018793 (F) свойство: положение лица относительно других, относительная позиция личности:

- д духовный статус 10018614;

- финансовый статус 10031299;

- физиологический статус 10014546;

- психологический статус 10015988;

- общественный статус 10018410;

- потребность 10012495;

- потребность ухода 10030878;

- потребность медицинского и социального ухода 10031350.

3. Запись пациента 10014178 (M).

4. Самоуход 10017661 (F) активность, осуществляется самостоятельно: забота о ресурсах, необходимых для нормального функционирования и удовлетворения основных индивидуальных и интимных потребностей, повседневной деятельности

5. Ведение здорового образа жизни 10008782 (F) поведение: предполагаемый способ идентификации, использования, управления и обеспечения средств медицинского ухода, связанный с заявлением о потребности медицинского ухода, а также получением помощи от других.

Система OLDCART. Медсестры должны соблюдать максимальную системность при проведении собеседования с пациентом. Такой системности способствует подход OLDCART, используемый для получения критической информации о пациенте и оценки болезни. В названии OLDCART каждая буква обозначает особый элемент информации.

O (onset) - начало медицинской проблемы: что вызывает беспокойство или жалобу больного?

L (location) - локализация недомогания (например, боли) и других сопровождающих проявлений;

D (duration) - длительность течения медицинской проблемы;

C (characteristic) - характер проблемы / недомогания;

A (aggravating factors) - факторы, отягчающие / ухудшающие / усиливающие медицинскую проблему / недомогание;

R (relieving factors) - смягчающие факторы, уменьшающие / ограничивающие усиление проблемы / недомогания;

$\mathrm{T}$ (treatment) - прежние способы поведения / лечения.

Оценка основных жизненных функций необходима для того, чтобы медсестра определила 


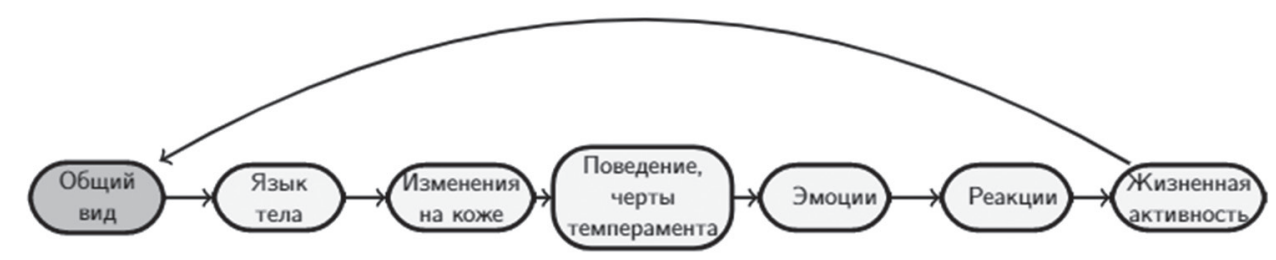

Рис 1. Элементы медсестринского обследования

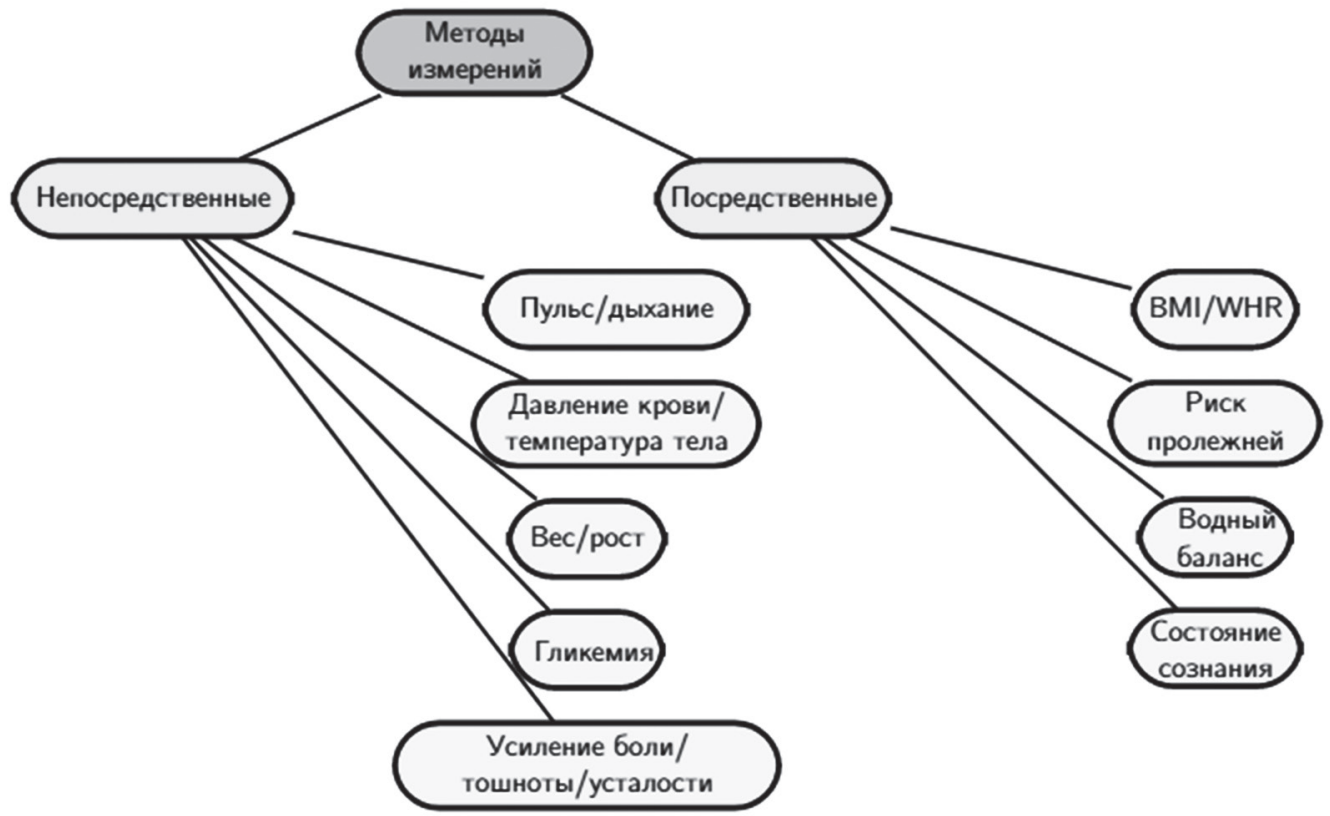

Рис 2. Измерения в медсестринской практике

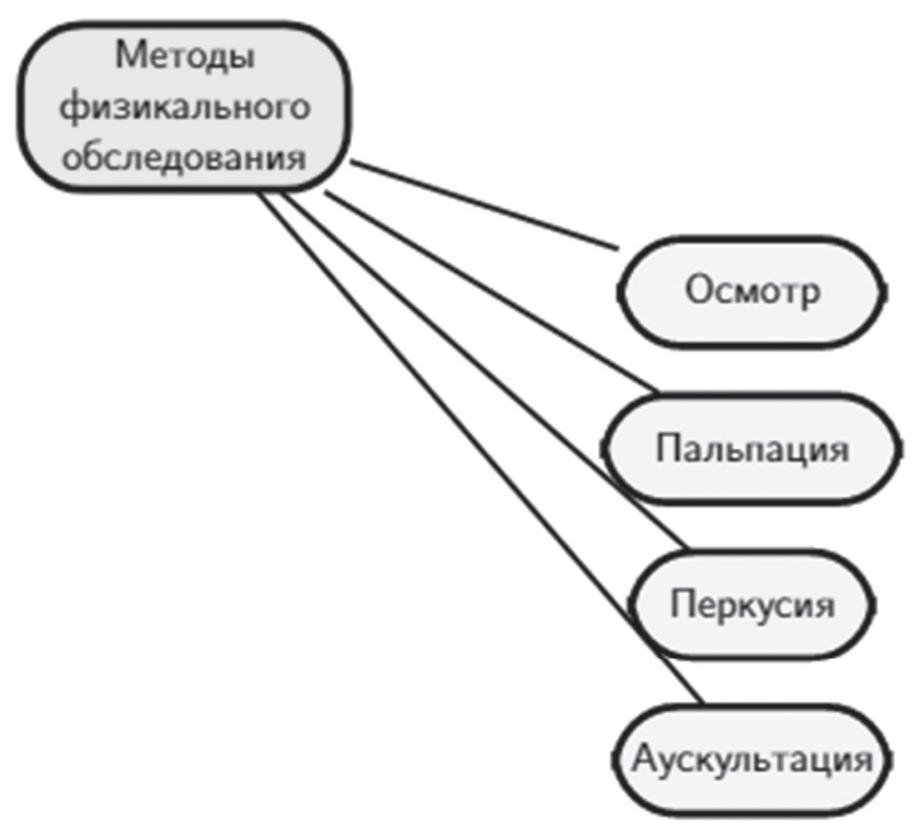

Рис 3. Методы физикального обследования 
состояние пациента, эффективность функционирования отдельных систем и органов, принимала меры для поддержания или изменения установленного порядка.

Оценка может охватывать три сферы функционирования человека, а именно биологическую, психическую и социальную.

Биологическая оценка должна содержать информацию о нормальном или нарушенном функционировании основных систем: дыхательной, сердечно-сосудистой (кровеносной), нервной, пищеварительной, мочевой, половой, терморегуляции.

Источником данных пациента могут быть сам пациент, его семья или другие близкие родственники.

При построении дерева решений на этапе оценки могут использоваться учебные наборы, атрибутами которых являются, например, элементы OLDCART. При этом атрибутом класса являются предложенные для пациента методы физикального обследования и измерения. Соответственно в узлах полученного дерева находятся элементы OLDCART, тогда как в листьях - необходимые методы обследования.

Этап 2: медсестринский диагноз. Сутью второго этапа процесса ухода является формулировка медсестринского диагноза, к установлению которого уполномочены исключительно медсестры. Признано, что установление медсестринского диагноза является одной из основных задач, имеющих фундаментальное и неоспоримое значение в медсестринской практике.

Медсестринский диагноз - это понятие (введено V. Fry в 1953 г.), которое принадлежит к главным функционирующим понятиям в уходе за больными и является отражением современной теоретической основы и философии ухода за больными, а также роли медсестры и ухода.

Диагноз определяет сферы и характер попечительской работы с пациентом / группой / средой.

Существуют следующие способы определения медсестринского диагноза:

- независимая функция медсестры, а также оценка личной реакции пациента на кризис развития болезни, неполноценность или другие стрессовые ситуации (Bircher, 1975).

- актуальные или потенциальные медицинские проблемы, к решению которых приставлены медсестры согласно своему образованию и опыту (Гордон, 1979).

- клиническое заключение, которое касается личности, семьи или группы лиц, выданное на основании сознательного и систематического процесса накопления данных и их анализа, составляет основу для планирования действий, за которые отвечает медсестра (Shoemaker, 1979).

- заключение, которое описывает реакции (состояние здоровья или изменения в актуальных / потенциальных интеракциях) человека или группы, медсестра может идентифицировать согласно своим полномочиям и выполнить (возможно, поручить) манипуляции с целью поддержания здоровья и предотвращения изменений (NANDA, 1979).

Правила диагностики. Важным вопросом является соблюдение определенных принципов:

- сильная корреляция диагноза(ов) и информации, полученной медсестрой в процессе этапа оценки;

- идентификация реальных и/или потенциальных угроз для здоровья и функционирования пациента, а также его безопасности;

- формулировка диагнозов, отражающих статус пациента: физиологический, психологический, социальный и культурно-духовный, а также уровень его подготовки, самостоятельности, жизненной активности, возможность справиться с болезнью самостоятельно, самооценка здоровья, уровень медицинских знаний и сознания, реакцию на существующую угрозу / диагностирование / болезнь / госпитализацию;

- использование международного языка, описывающего классификации медсестринской практики, например ICNP (рис. 4);

- документирование диагнозов способом, обеспечивающим и облегчающим определение ожидаемых результатов и плана ухода.

Формулировка медсестринских диагнозов. В литературе чаще всего чередуется несколько классических подходов к способам формулировки медсестринских диагнозов, которые записываются как:

- заключение, состоящее из одной части (например, боль, удушье, страх);

- заключение, состоящее из двух частей, (например, риск возникновения пролежней, вызванный недержанием мочи и стула; расстройства газового обмена, обусловленные спазмом гладких мышц бронхов);

- заключение из трех частей (например, снижение толерантности к физической нагрузке, вызванное расстройствами газового обмена, проявляется одышкой и утомляемостью; испуг по поводу операционной процедуры, проявляется взволнованностью, плачем и бессонницей). 


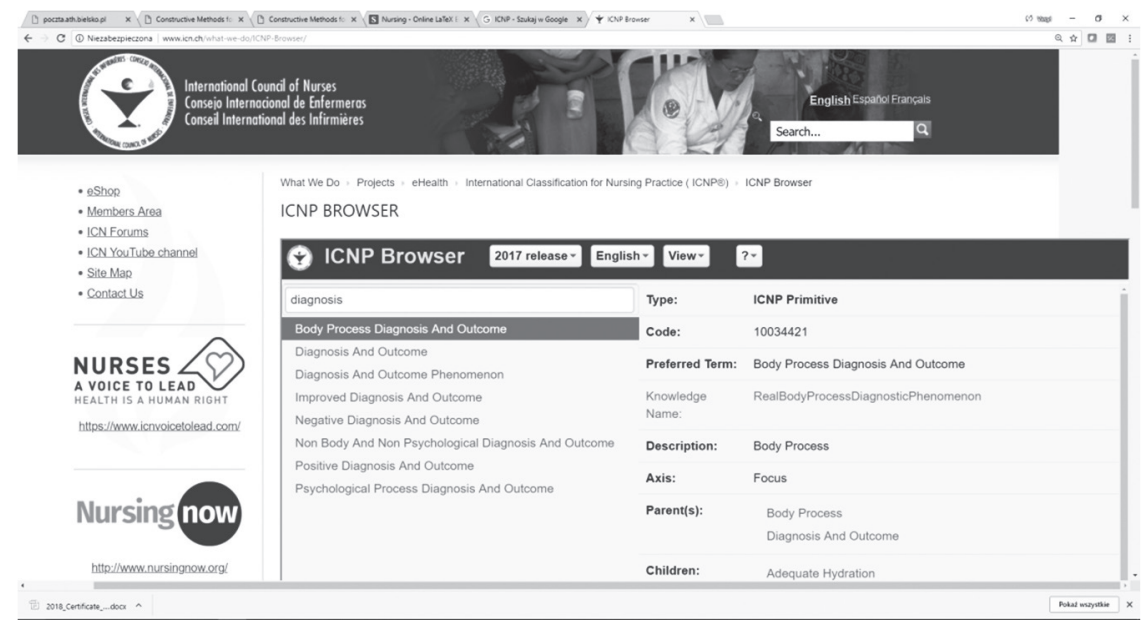

Рис 4. Браузер международного классификатора медсестринской практики ICNP

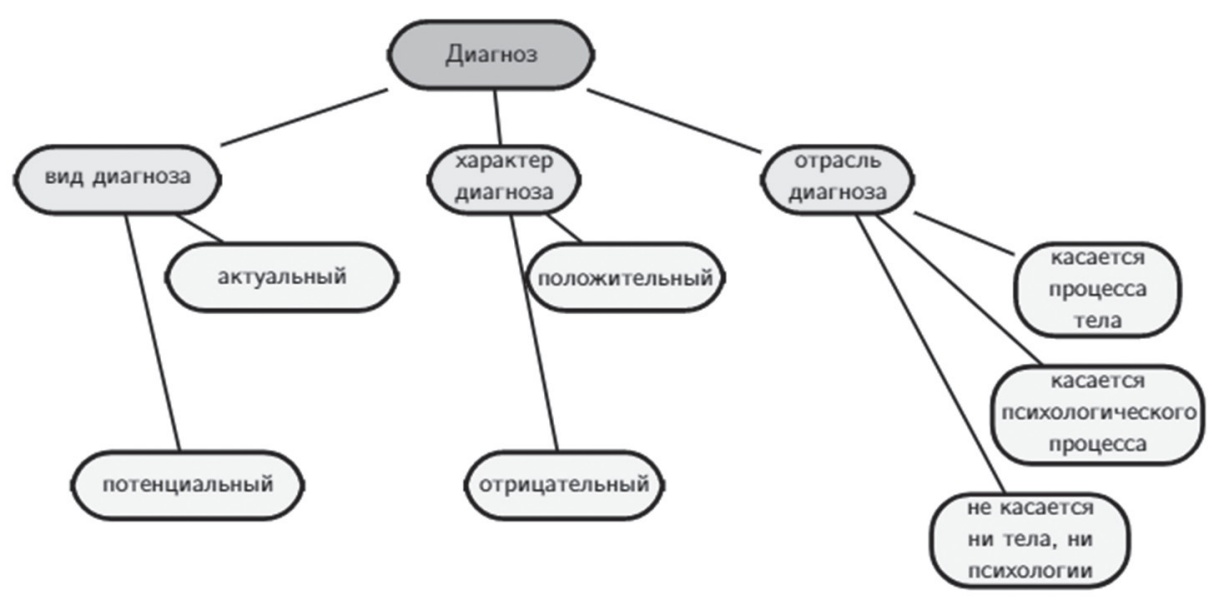

Рис 5. Дифференциальная диагностика ICNP

Классификатор ICNP предлагает использовать с целью формулирования медсестринского диагноза правило PES (проблема / этиология / симптом), в котором «Р» обозначает диагностическую категорию, «Е» — определение этиологических факторов / факторов риска, а «S» - объективные и субъективные проявления, подтверждающие распознавание проблемы.

Диагнозы ICNP. Следует подчеркнуть, что актуальная версия ICNP (с 2015 года) содержит 805 медсестринских диагнозов, которые облегчают медсестре формулировку и документирование информации на первом этапе процесса ухода, оценку статуса пациента в целостном измерении.

При построении дерева решений на этапе формулировки медсестринского диагноза могут использоваться учебные наборы, атрибутами которых являются элементы OLDCART и методы обследования. При этом атрибутом класса является диагноз ICNP. Соответственно, в узлах полученного дерева могут находиться элементы OLDCART и результаты методов обследований, тогда как в листьях - диагнозы ICNP в формате PES.

Этап 3: планирование (ухода). Планирование медсестринского ухода заключается в решении вопроса о том, что и каким образом должно быть выполнено для пациента / пациентом / при пациенте, чтобы можно было достичь оптимального состояния. Следует принять решение, кто будет реализовывать отдельные манипуляции или все из них в пользу объекта медсестринского ухода.

После согласования (лучше вместе с пациентом / уполномоченными лицами) списка диагнозов медсестра должна предоставить каждому из них определенный приоритет и сформулировать для каждого четкий, измеряемый, ожидаемый и возможный для достижения результат ухода. 
Этап 4: имплементация. После формулировки соответствующего и особого для каждого пациента плана ухода медсестра начинает его имплементацию, реализуя медсестринские манипуляции, которые могут происходить в различном временном промежутке (от нескольких минут / часов до нескольких недель или даже месяцев).

Имплементация плана ухода должна происходить способом, обеспечивающим получателю услуг безопасность в четко определенном времени. Обычно манипуляции, выполняемые медсестрами, касаются областей, связанных с предоставлением услуг: опекунских, профилактических, терапевтических, реабилитационных, медицинской неотложной помощи.

Этап 5: эвалуация. Смыслом эвалуации является сравнение статуса пациента, установленного на первом этапе процесса ухода, с полученным после выполнения определенных манипуляций (охватывающих профессиональные и непрофессиональные действия, самоуход). В ходе этой познавательной активности медсестра должна ответить на некоторые вопросы, включая, например:

- кто и/или что составляло препятствие / затруднения в течение всего процесса ухода и привело к окончательному результату ухода (например, нехватка оборудования, недостаточно укомплектованный медсестринский штат, организационные решения, нежелание / отказ со стороны пациента) и каким образом привело к появлению непредвиденных результатов;

- как следует вести себя в дальнейшем, особенно если достигнутый эффект был половинчатый или вообще не удалось достичь планируемого результата.

Выводы. Итак, процесс ухода - это научный метод работы медсестры с получателем медсестринских услуг, основанный на целостной концепции ухода, которая определяет систематизированный цикл действий. В процессе ухода медсестра использует критическое мышление и элементы клинической мысли, что требует умения интерпретации и применения результатов научных исследований. Процесс ухода состоит из пяти этапов: оценки, медсестринского диагноза, планирования ухода, его имплементации и эвалуации.

Оценка функционирования больного служит для идентификации актуальных и потенциальных проблем ухода за пациентом и его потребностей; в свою очередь, обуславливает сферу и характер медсестринского ухода.

Установленный медсестринский диагноз должен быть кратким, ясным, четким и понятным для каждой медсестры и всех членов коллектива, с оптимальным использованием международного стандарта медсестринской терминологии ICNP.

Существенным элементом планирования ухода является определение вида и сферы медсестринских манипуляций, позволяющих достичь запланированных предварительно результатов, с использованием в медсестринской практике научных доказательств (evidence based nursing, EBN).

Документирование получаемых данных должно происходить своевременно, согласно отраслевым установкам, с предпочтением электронной записи. Согласно ICNP медсестринская документация включает листок индивидуального медсестринского ухода, который состоит из листа медсестринского интервью, листа оценки состояния пациента, плана медсестринского ухода, медсестринских рекомендаций при выписке из больницы, а также медсестринского отчета.

Анализ решения может быть полезным подходом в медсестринстве. Он позволяет подробно рассмотреть проблемные решения, использовать экспериментальные доказательства для обоснования решения и рекомендовать оптимальные решения в сложных ситуациях. Анализ решения также способствует целостному уходу за больным, поскольку такой подход может быть применен на всех этапах ухода и для различных вариантов лечения.

Четко структурируя решение, которое будет принято в форме дерева, можно установить, как и почему было принято конкретное решение. Это может стать важным обоснованием клинических решений в медсестринской практике. 


\section{Литература.}

1. Марценюк В. П. Дистанційна система навчання як засіб для здобуття освітньої кваліфікації бакалавра та магістра медсестринства в Тернопільському державному медичному університеті імені I. Я. Горбачевського / В. П. Марценюк, Н. І. Рега, В. Є. Городецький // Медична інформатика та інженерія. 2013. — № 2. - С. 33-36.

2. Марценюк В. П. Телемедичні технології в США: організаційне, програмне та апаратне забезпечення / В. П. Марценюк, О. Л. Ковальчук, А. А. Лепявко // Медична інформатика та інженерія. - 2009.№ 2. - С. 22-31.

3. Медсестринська освіта в Університеті Південної Кароліни Апстейт (США) / за ред. Л. Я.Ковальчука. - Тернопіль : ТДМУ, 2006. - 398 с.

4. Coenen A. Development of terminology subsets using

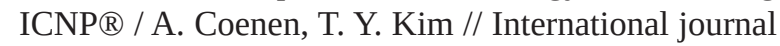
of medical informatics. — 2010. — Vol. 79, No. 7. P. 530-538.

5. Corbin J. M. A nursing model for chronic illness management based upon the trajectory framework / J. M. Corbin // Research and theory for nursing practice. - 1991. - Vol. 5, No. 3. - P. 155.

6. Dowding D. Using decision trees to aid decision-making in nursing / D. Dowding, C. Thompson // Nursing times. - 2004. - Vol. 100, No. 21. - P. 36-39.

7. Häyrinen K. Evaluation of electronic nursing documentation - Nursing process model and standardized terminologies as keys to visible and transparent nursing / K. Häyrinen, J. Lammintakanen, K. Saranto // International journal of medical informatics. - 2010. - Vol. 79, No. 8. - P. 554-564.

8. Wilkinson J. M. Nursing process and critical thinking / J. M. Wilkinson. — New Jersey : Prentice Hall, 2001. — 3rd ed.

\section{References.}

1. Martsenyuk, V. P., Rega, N. I., \& Gorodets'kii, V. Ye. (2013). Distantsiina sistema navchannya yak zasib dlya zdobuttya osvitn’oi kvalifikatsii bakalavra ta magistra medsestrinstva v Ternopil's'komu derzhavnomu medichnomu universiteti imeni I. Ya. Gorbachevs’kogo [Distance learning system as a means for obtaining the educational qualification of a bachelor and master of nursing in I. Gorbachevsky Ternopil State Medical University]. Medichna informatika ta inzheneriya (Medical informatics and engineering), 2, 33-36.

2. Martsenyuk, V. P., Koval'chuk, O. L., \& Lepyavko, A. A. (2009). Telemedichni tekhnologii v SShA: organizatsiine, programne ta aparatne zabezpechennya [Telemedicine technologies in the USA: organization, software and hardware]. Medichna informatika ta inzheneriya (Medical informatics and engineering), 2, 22-31.

3. Koval'chuk, L. Ya. (Ed.) (2006). Medsestrins'ka osvita v Universiteti Pivdennoi Karolini Apsteit (SShA) [Nursing Education at the University of South Carolina Apstate (USA)]. Ternopil': TSMU.

4. Coenen, A., \& Kim, T. Y. (2010). Development of terminology subsets using ICNP ${ }^{\circledR}$. International journal of medical informatics, 79(7), 530-538. doi: 10.1016/j. ijmedinf.2010.03.005.

5. Corbin, J. M. (1991). A nursing model for chronic illness management based upon the trajectory framework. Research and Theory for Nursing Practice, 5(3), 155.

6. Dowding, D., \& Thompson, C. (2004). Using decision trees to aid decision-making in nursing. Nursing times, 100(21), 36-39.

7. Häyrinen, K., Lammintakanen, J., \& Saranto, K. (2010). Evaluation of electronic nursing documentation Nursing process model and standardized terminologies as keys to visible and transparent nursing. International journal of medical informatics, 79(8), 554-564. doi: 10.1016/j.ijmedinf.2010.05.002

8. Wilkinson, J. M. (2001). Nursing process and critical thinking. New Jersey: Prentice Hall. 